\title{
Cognitive content specificity in anxiety and depressive disorder symptoms: a twin study of cross-sectional associations with anxiety sensitivity dimensions across development
}

\author{
H. M. Brown ${ }^{1}$ t, M. A. Waszczuk ${ }^{1}$ t, H. M. S. Zavos $^{1}$, M. Trzaskowski ${ }^{1}$, A. M. Gregory ${ }^{2}$ and T. C. Eley $^{1 *}$ \\ ${ }^{1}$ Social, Genetic and Developmental Psychiatry Centre, Institute of Psychiatry, King's College London, UK \\ ${ }^{2}$ Department of Psychology, Goldsmiths, University of London, UK
}

Background. The classification of anxiety and depressive disorders has long been debated and has important clinical implications. The present study combined a genetically sensitive design and multiple time points to investigate cognitive content specificity in anxiety and depressive disorder symptoms across anxiety sensitivity dimensions, a cognitive distortion implicated in both disorders.

Method. Phenotypic and genetic correlations between anxiety sensitivity dimensions, anxiety and depressive disorder symptoms were examined at five waves of data collection within childhood, adolescence and early adulthood in two representative twin studies ( $n$ pairs $=300$ and 1372).

Results. The physical concerns dimension of anxiety sensitivity (fear of bodily symptoms) was significantly associated with anxiety but not depression at all waves. Genetic influences on physical concerns overlapped substantially more with anxiety than depression. Conversely, mental concerns (worry regarding cognitive control) were phenotypically more strongly associated with depression than anxiety. Social concerns (fear of publicly observable symptoms of anxiety) were associated with both anxiety and depression in adolescence. Genetic influences on mental and social concerns were shared to a similar extent with both anxiety and depression.

Conclusions. Phenotypic patterns of cognitive specificity and broader genetic associations between anxiety sensitivity dimensions, anxiety and depressive disorder symptoms were similar at all waves. Both disorder-specific and shared cognitive concerns were identified, suggesting it is appropriate to classify anxiety and depression as distinct but related disorders and confirming the clinical perspective that cognitive therapy is most likely to benefit by targeting cognitive concerns relating specifically to the individual's presenting symptoms across development.

Received 9 December 2013; Revised 24 February 2014; Accepted 1 March 2014

Key words: Anxiety, anxiety sensitivity dimensions, cognitive specificity, depression, development, genetics, twins.

\section{Introduction}

Anxiety and depressive disorders are common and frequently co-morbid (Axelson \& Birmaher, 2001). The distinctiveness of anxiety and depression is the subject of ongoing nosological debate concerning their classification in the updated psychiatric diagnostic manual, DSM-5 (Andrews et al. 2008). Some researchers question the utility of considering anxiety and depressive disorders as distinct clinical categories, given the considerable similarities in their presentation, aetiology and treatment (Axelson \& Birmaher, 2001). However,

* Address for correspondence: Professor T. C. Eley, Social, Genetic and Developmental Psychiatry Centre, Institute of Psychiatry, Box PO80, De Crespigny Park, London SE5 8AF, UK.

(Email: thalia.eley@kcl.ac.uk)

+ These authors contributed as joint first authors. there are important distinctions. Anxiety and depressive disorders can occur in isolation, twin studies reveal that whereas genetic influences are largely shared, environmental influences are generally distinct (Kendler et al. 1987) and preliminary neuroimaging studies show differential neural correlates (Phan et al. 2002; Vytal \& Hamann, 2010).

The classification of anxiety and depression also has important clinical implications. If anxiety and depression are considered a single disorder then a unified treatment should be recommended, whereas discrete disorders suggest distinct interventions are required. Cognitive behavioural therapy (CBT) is a leading treatment for both anxiety and depression globally and is recommended as the first-line treatment in the USA (AACAP, 2007) and the UK (NICE, 2011). The premise of CBT is the modification of maladaptive cognitions maintaining emotional symptoms. The 


\section{H. M. Brown et al.}

cognitive content specificity (CCS) hypothesis proposes that, although anxious and depressed individuals both have distorted cognitions, the content differs across these disorders (Beck \& Perkins, 2001). Specifically, it is hypothesized that depressed individuals tend to think negatively about the self and focus on experiences of loss whereas anxious individuals focus on perceived threat or danger. In line with this model, the cognitive concerns targeted in CBT tend to vary across anxiety and depressive disorders (Brewin, 1996).

Given the implications of the CCS hypothesis for classifying and treating anxiety and depressive disorders, cognitive distortions associated with anxiety and depression need to be studied together to investigate the extent to which they are specific to each disorder or shared between them. Little is known about the role of shared and specific cognitions in the development of anxiety and depressive disorders in young people.

\section{Anxiety sensitivity: associations with anxiety and depression}

Anxiety sensitivity is of particular interest when considering common and specific cognitive content in anxiety and depression. Anxiety sensitivity refers to an enhanced sensitivity towards symptoms of anxiety such as heart palpitations or worry, with a belief that these are harmful (Taylor, 1999). The distinct nature of anxiety sensitivity compared to trait anxiety has been well established, in relation to both self-reported symptoms and laboratory-induced anxiety responses (McNally \& Rapee, 1996; Rabian et al. 1999). Anxiety sensitivity also predicts future anxiety symptoms above and beyond concurrent anxious symptoms (Weems et al. 1998; McLaughlin et al. 2007; Waszczuk et al. 2013). Of note, despite its initial conceptualization as a risk factor for panic disorder (Reiss \& McNally, 1985), anxiety sensitivity has been found to be associated with a wide range of anxiety symptoms and disorders and with depression (Weems et al. 1997; Naragon-Gainey, 2010; Waszczuk et al. 2013).

One possible reason for this wide range of associations is that anxiety sensitivity measures include multiple subscales (e.g. physical, mental and social concerns) that may be differentially associated with anxiety and depression.

\section{Anxiety sensitivity: subscale analyses}

Early investigations of anxiety sensitivity found that the physical concerns dimension (fear of biological symptoms; e.g. 'When my stomach hurts, I worry that I might be really sick') was more frequently associated with anxiety than depression (Joiner et al. 2002;
Muris, 2002). The relationship of physical concerns with anxiety remained significant after controlling for co-occurring depression symptoms (Taylor et al. 1996; Schmidt et al. 1998; Dehon et al. 2005). Conversely, the mental concerns subscale, which depicts worries regarding cognitive control over anxiety symptoms (e.g. 'When I am afraid, I worry I might be going crazy'), is more frequently associated with depression (Muris, 2002), although other studies report associations with both anxiety and depression (Taylor et al. 1996; Schmidt et al. 1998; Dehon et al. 2005) or with anxiety but not depression (Joiner et al. 2002). The social concerns subscale, reflecting fears of publicly observable symptoms of anxiety (e.g. 'I don't like to let my feelings show'), seems to be associated with both anxiety and depression (Dehon et al. 2005), although others show stronger association with anxiety symptoms (Taylor et al. 1996; Schmidt et al. 1998). Although there is debate regarding the specific number and content of anxiety sensitivity subscales, confirmatory factor analytic studies (Wright et al. 2010) and a twin study by our group (Brown et al. 2012) support a hierarchical structure of anxiety sensitivity with three dimensions representing physical, social and mental concerns.

Mixed results across studies, particularly for mental and social concerns dimensions, could represent developmental differences in associations between anxiety sensitivity dimensions, anxiety and depression. However, a study of global anxiety sensitivity from our team found consistent associations with anxiety and depression symptoms across multiple time points in adolescence (Zavos et al. 2012b). Additionally, as multiple age groups are rarely included in single studies, particularly examining associations with anxiety sensitivity dimensions, mixed results could simply reflect differences in sample characteristics (e.g. clinical versus non-clinical groups) and methodologies (e.g. derivation of anxiety sensitivity dimensions) across studies.

\section{Anxiety sensitivity: genetic and environmental influences}

Examining genetic and environmental associations between cognitive content, anxiety and depression can help to disentangle common and specific influences on these problems. Our team has previously shown a large genetic overlap between anxiety sensitivity and anxiety symptoms (0.89) in childhood (Waszczuk et al. 2013) and with both anxiety (0.86-0.87) and depression symptoms $(0.70-0.76)$ in adolescence (Zavos et al. 2010). This is in line with the generalist genes hypothesis (Eley, 1997), which proposes that psychiatric traits that co-vary have similar genetic influences that account for their co-morbidity whereas non-shared 
environmental influences are largely trait specific. However, to date, there are no studies examining aetiological influences on associations between specific anxiety sensitivity dimensions, anxiety and depression in any age range.

\section{The current study}

The current study examined cross-sectional, phenotypic and aetiological associations between anxiety sensitivity dimensions, anxiety and depressive disorder symptoms at five waves of data collection within three different stages in development: childhood, adolescence and early adulthood. To our knowledge this is the first study to take a developmental perspective and combine both phenotypic and genetically sensitive data to address this question. This allows us not only to explore the CCS hypothesis at different ages but also to identify whether associations are mirrored at the aetiological level.

Several hypotheses were generated. First, the physical concerns dimension of anxiety sensitivity was expected to be more strongly associated with anxiety than depressive disorder symptoms whereas mental concerns would be more strongly associated with depression than anxiety, and social concerns would be associated with both anxiety and depression to a similar extent. Second, we anticipated that these relationships would generally be consistent at the different data collection waves within childhood, adolescence and adulthood, in line with limited multiple time-point studies of global anxiety sensitivity. Third, in line with the generalist genes hypothesis, we hypothesized that genetic associations would mirror the pattern of phenotypic associations. We expected stronger genetic correlations between physical concerns and anxiety and between mental concerns and depression, with social concerns showing a similar genetic overlap with both anxiety and depressive disorders symptoms.

\section{Method}

\section{Participants}

The present analyses combined data from two longitudinal twin and sibling datasets: the Emotions, Cognitions, Heredity and Outcome (ECHO) and Genesis G12-19 (G1219) studies. ECHO is a spin-off of a larger population sample with most of the twin pairs being selected for heightened parent-report anxiety at 7 years. G1219 is an unselected twin and sibling study. Full recruitment details are provided elsewhere (Eley et al. 2007; McAdams et al. 2013). Both studies were approved by the appropriate ethics committees (Research Ethics Committee, Institute of Psychiatry, King's College London and Goldsmiths, University of
London). Informed consent was obtained from parents of all children aged under 16 years and from participants over 16 themselves. Zygosity was determined using parent-rated questionnaires (Cohen et al. 1975; Price et al. 2000) and DNA sequencing in uncertain cases. The current report focuses on five waves of data collected during childhood, adolescence and adulthood: wave 1 (mean age $=8$ years) and wave 2 (mean age $=10$ ) from ECHO, and waves 3 (mean age=15), 4 (mean age $=17$ ) and 5 (mean age=20) from G1219. Sample characteristics are shown in Table 1. There were wide age ranges for waves $3-5$, reflecting the inclusion of siblings in G1219. However, the majority of the sample at each wave conferred much narrower age ranges (e.g. $>90 \%$ 18-22 years at wave 5$)^{1}+$.

\section{Measures}

Anxiety sensitivity

Anxiety sensitivity was assessed using the Children's Anxiety Sensitivity Index (CASI; Silverman et al. 1991) at waves 1-4 and the Anxiety Sensitivity Index (ASI; Reiss et al. 1986) at wave 5. Both involve participants completing items reflecting fear of anxiety sensations and have sound psychometric properties. Anxiety sensitivity dimensions representing physical, social and mental concerns were defined based on previous factor analyses in the G1219 study (Brown et al. 2012). Physical concerns consisted of 12 items assessing worries regarding physical symptoms of anxiety. Social and mental concerns dimensions each contained three items relating to publicly observable symptoms of anxiety and worries about cognitive control respectively. At wave 5, physical and social concerns dimensions had 11 and two items respectively because the ASI had fewer overall items than the CASI. Dimension scores were calculated by summing constituent items for each subscale.

\section{Anxiety}

DSM-based anxiety symptoms were assessed using the Screen for Child Anxiety Related Emotional Disorders (SCARED; Birmaher et al. 1999) at waves 1 and 2 (mean ages 8 and 10) and the Spence Children's Anxiety Scale (SCAS; Spence, 1998) at waves 3 and 4 (mean ages 15 and 17). At wave 5 (mean age 20), an adult variant (Gregory et al. 2011) of the anxiety items from the Revised Children's Anxiety and Depression Scales (RCADS; Chorpita et al. 2000) was used. All measures represent self-report questionnaires tapping common anxiety symptoms and show sound psychometric

† The notes appear after the main text. 
Table 1. Sample characteristics and descriptive statistics for anxiety sensitivity dimensions, anxiety and depressive disorder symptoms in childhood, adolescence and adulthood

\begin{tabular}{llllll}
\hline & $\begin{array}{l}\text { Wave } 1 \\
\text { (ECHO) }\end{array}$ & $\begin{array}{l}\text { Wave 2 } \\
\text { (ECHO) }\end{array}$ & $\begin{array}{l}\text { Wave 3 } \\
(\text { G1219) }\end{array}$ & $\begin{array}{l}\text { Wave } 4 \\
(\text { G1219) }\end{array}$ & $\begin{array}{l}\text { Wave } 5 \\
(\text { G1219) }\end{array}$ \\
\hline$n$ (pairs) & 300 & 250 & 1,372 & 866 & 896 \\
Female/Male, $n$ (\%) & $169.5(57) / 130.5(43)$ & $141(56) / 109(44)$ & $768(56) / 604(44)$ & $520(60) / 346(40)$ & $547(61) / 349(39)$ \\
Age (years.months), mean (range) & $8.6(8.2-8.11)$ & $10.1(9.7-10.10)$ & $15.0(12.0-21.0)$ & $17.0(14.0-23.0)$ & $20.0(18.0-27.0)$ \\
Zygosity (MZ/DZS/DZO/Sib) & $100 / 82 / 117 / 0$ & $83 / 69 / 98 / 0$ & $350 / 313 / 334 / 330^{\mathrm{a}}$ & $234 / 207 / 232 / 182^{\mathrm{a}}$ & $230 / 214 / 232 / 201^{\mathrm{a}}$ \\
Anxiety sensitivity & $31.31(6.24)$ & $30.32(5.51)$ & $28.73(5.55)$ & $25.65(5.72)$ & $31.52(9.41)$ \\
Physical & $21.01(4.80)$ & $20.22(4.37)$ & $18.61(4.32)$ & $16.14(4.17)$ & $20.47(7.37)$ \\
Social & $5.981 .47)$ & $6.19(1.20)$ & $6.32(1.43)$ & $5.92(1.69)$ & $6.58(1.85)$ \\
Mental & $4.33(1.47)$ & $3.91(1.17)$ & $3.80(1.14)$ & $3.60(1.07)$ & $4.48(2.10)$ \\
Anxiety & $29.39(12.63)$ & $25.17(11.59)$ & $28.85(13.66)$ & $20.62(12.80)$ & $25.06(14.88)$ \\
Depression & $10.27(6.94)$ & $8.22(5.82)$ & $8.08(6.65)$ & $6.25(5.33)$ & $6.45(5.73)$ \\
\hline
\end{tabular}

ECHO, Emotions, Cognitions, Heredity and Outcome; MZ, monozygotic; DZS, dizygotic, same-sex pairs; DZO, dizygotic, opposite-sex pairs; Sib, siblings.

${ }^{a}$ The numbers of twin pairs do not add up to totals because some of the twins were of unknown zygosity (wave $3=45$, wave $4=11$, wave $5=19$ ). These pairs were excluded from the genetic analyses.

Summary statistics are presented on untransformed and unregressed variables for comparison with other published samples.

Different measures of anxiety sensitivity, anxiety and depression were used at different waves, thus the means cannot be compared across some waves.

The wider age ranges at waves $3-5$ reflect the inclusion of siblings. The majority of the sample at each time point confer much narrower age ranges (e.g. $>90 \% 18-22$ at wave 5).

properties. Responses were summed across items on each measure to create total anxiety scores.

All analyses at waves 1 and 2 were repeated removing one item from the SCARED that overlapped with the CASI: 'When I get frightened, I feel like I am going crazy'. However, the results did not differ meaningfully so analyses with full measures are reported here.

\section{Depression}

DSM-based depressive disorder symptoms were assessed using the Children's Depression Inventory (CDI; Kovacs, 1985) in ECHO (waves 1 and 2) and the Short Mood and Feelings Questionnaire (SMFQ; Angold et al. 1995) in G1219 (waves 3-5). Both selfreport measures demonstrate sound psychometric properties. Total depression scores were created by summing response across all items.

\section{Analyses}

Phenotypic analyses

Phenotypic associations between anxiety sensitivity dimensions, anxiety and depression were examined at each wave using full correlations. Owing to substantial covariance between anxiety sensitivity dimensions and co-occurrence of anxiety and depressive disorders symptoms, partial correlations were used at each wave to tease apart phenotypic specificity. Pair-wise partial correlations controlled for associations with other variables (e.g. associations between physical concerns and anxiety controlled for the other anxiety sensitivity dimensions and depression).

\section{Genotypic analyses}

Aetiological associations between anxiety sensitivity dimensions, anxiety and depressive disorders symptoms were examined at each wave using structural equation twin modelling. By comparing the degree of similarity of monozygotic (MZ) twins (sharing all of their segregating genes) to dizygotic (DZ) twins (sharing half of their segregating genes on average), the twin design decomposes the variance within a variable into additive genetic influences (A), common environmental influences that make family members more alike (C) and non-shared, individual-specific environmental influences (E). The genetic and environmental overlap between multiple measures can be examined by comparing the MZ:DZ ratio of cross-twin, cross-trait covariances.

Prior to twin analyses, all variables were regressed for the effects of age and sex to meet twin modelling assumptions and mapped onto a standard normal distribution using the rank-based van der Waerden 


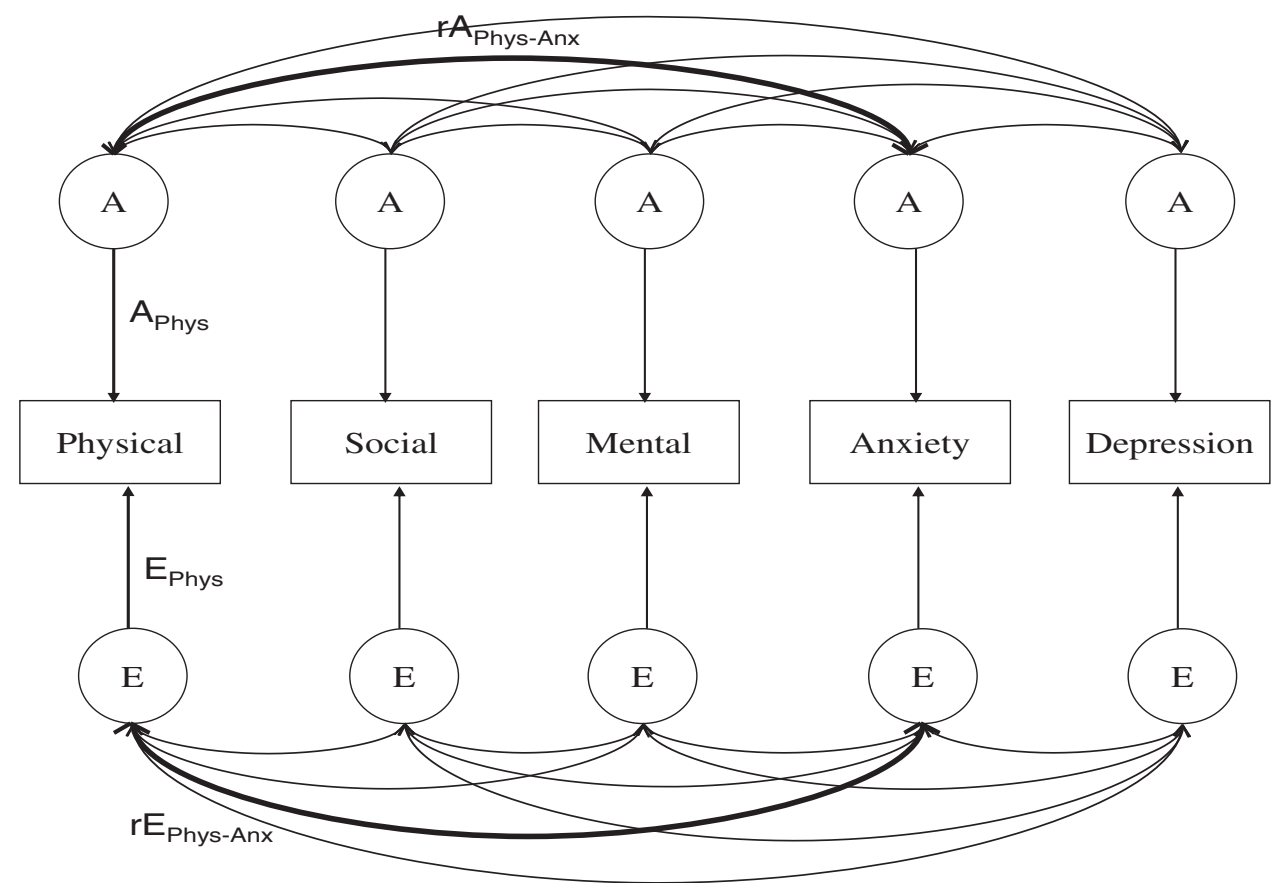

Fig. 1. Correlated factors solution showing genetic and environmental associations between anxiety sensitivity subscales (physical, social and mental concerns) and anxiety and depressive disorder symptoms. Phys, Physical concerns; A, additive genetic; $\mathrm{E}$, non-shared environment; $r \mathrm{~A}$, genetic correlation; $r \mathrm{E}$, non-shared environmental correlation. Paths in bold are highlighted and labelled for descriptive purposes only. For example, the path labelled $\mathrm{A}_{\text {Phys }}$ represents the genetic effects on the physical concerns dimension of anxiety sensitivity and the path labelled $r \mathrm{~A}_{\text {Phys-Anx }}$ depicts the degree to which genetic influences on the physical concerns dimensions of anxiety sensitivity are correlated with genetic effects on anxiety symptoms. Similarly, $r \mathrm{E}_{\text {Phys-Anx }}$ represents the degree to which non-shared environmental factors influencing physical concerns are correlated with those influencing anxiety symptoms. Shared environmental estimates $(\mathrm{C})$ and correlations $(r \mathrm{C})$ were also calculated. However, these were non-significant so for simplicity are not shown in the figure. Estimates for $\mathrm{C}$ and $r \mathrm{C}$ are reported in Tables S1 and S3 respectively.

transformation to correct for skew. Twin models were fitted using the OpenMx program (Boker et al. 2011) in R (RDC Team, 2010), a structural equation modelling package for the analysis of genetically informative data that controls for the non-independence of family members. Sampling weights were incorporated in ECHO twin models to account for the selected nature of the sample (Lau et al. 2007). Model fit to a saturated model was assessed for both univariate and multivariate models at each wave using minus twice the log likelihood (-2LL) of the observations and the Akaike information criterion (AIC). Univariate analyses assessing the influences of $\mathrm{A}, \mathrm{C}$ and $\mathrm{E}$ on all variables were conducted at each wave. Sex differences were examined to inform multivariate modelling. Because of the sample size, sex differences were only examined in the G1912 sample to inform twin modelling. Scalar (i.e. variance) sex differences were found for all variables except for social concerns. Therefore, variance differences were included in the model-fitting analyses.

Multivariate correlated factors solutions examined the genetic and environmental relationships between anxiety sensitivity dimensions, anxiety and depression at each wave. The correlated factor solution (Fig. 1) assumes that each variable has unique genetic and environmental influences (e.g. $A_{\text {Phys, }} C_{\text {Phys, }} E_{\text {Phys }}$ ) but that these are correlated with one another (e.g. $r \mathrm{~A}_{\text {Phys-Anx }}, r \mathrm{C}_{\text {Phys-Anx }}$ and $r \mathrm{E}_{\text {Phys-Anx }}$ respectively for genetic, shared environment and non-shared environment correlations between physical concerns and anxiety). Thus, the curved arrow from the A term above the physical anxiety sensitivity subscale to the A term above the anxiety scale represents the genetic correlation between these two variables.

The relative strength of genetic and non-shared environmental estimates for each variable and for correlations between variables was compared using likelihood-based confidence intervals (CIs). Nonoverlapping CIs indicate significant differences.

Finally, the focus of the current results was on associations between different anxiety sensitivity subscales and anxiety and depressive symptoms. Phenotypic and genetic associations among anxiety sensitivity subscales, and also between anxiety and 
depression, are presented elsewhere (Zavos et al. 2010; Brown et al. 2012).

\section{Ethical standards}

All procedures contributing to this work complied with the ethical standards of the relevant national and institutional committees on human experimentation and with the Helsinki Declaration of 1975, as revised in 2008.

\section{Results}

\section{Descriptive statistics}

Descriptive statistics of all measures are presented in Table 1. Descriptive statistics results are reported on raw untransformed data to facilitate comparisons with other studies. The majority of variables demonstrated substantial internal consistency at all waves $(\alpha=0.79-0.94$ for anxiety and depression; $\alpha=0.25-0.86$ for anxiety sensitivity subscales). Estimates were somewhat lower for social and mental concerns dimensions because there were fewer items within those subscales. However, estimates were comparable to other samples (Walsh et al. 2004; Joiner et al. 2002).

\section{Phenotypic results}

Full and partial Pearson correlations are presented in Table 2. For the physical concerns dimensions of anxiety sensitivity, full correlations indicated significantly stronger associations with anxiety than depressive disorder symptoms at all waves ( $r_{\text {Phys-Anx }}=0.52-0.71$, $\left.r_{\text {Phys-Dep }}=0.25-0.51\right)$. This was confirmed by partial correlations. The association between physical concerns and anxiety remained significant whereas partial correlations with depression became non-significant and near-zero at most waves.

Social concerns were associated with both anxiety and depression to a similar extent at all ages ( $r_{\text {Soc-Anx }}$ $\left.=0.20-0.40, r_{\text {Soc-Dep }}=0.05-0.43\right)$, although associations with depression were weaker at waves 1 and 2 (mean ages 8 and 10 respectively). Partial correlations revealed no association between social concerns and either anxiety or depression at waves 1,2 and 5 but significantly stronger associations with depression than anxiety at the time points covering adolescence (waves 3 and 4).

Finally, full correlations for mental concerns revealed similar associations with anxiety and depressive disorder symptoms at all waves ( $r_{\text {Ment-Anx }}=0.36-0.60$, $\left.r_{\text {Ment-Dep }}=0.28-0.54\right)$. Partial correlations showed a tendency for stronger associations with depression than anxiety, which reached significance at wave 4
[0.28 (95\% CI 0.22-0.34) and 0.10 (95\% CI 0.03-0.17) for depression and anxiety respectively].

\section{Genetic associations}

\section{Univariate estimates}

Univariate genetic and environmental estimates indicated small to moderate genetic effects $(0.12-0.46)$, small but non-significant shared environmental influences (0.00-0.12) and large non-shared environmental influences $(0.49-0.84)$ on all variables (see online Supplementary Table S1). Depression at wave 2 was an exception, being influenced by moderate shared environmental factors with no genetic influence (see note to Table S1 for further details).

\section{Multivariate estimates}

Genetic and non-shared environmental correlations between the variables at each wave are shown in Table 3 (fit statistics in Supplementary Table S2). Because of small non-significant shared environmental estimates on all variables, shared environmental correlations were modelled but were non-significant and thus are not interpreted further (see Supplementary Table S3).

Genetic correlations between the physical concerns dimensions of anxiety sensitivity and anxiety and depression are given in the first column of Table 3 . Physical concerns showed substantial genetic overlap with anxiety symptoms at all ages $\left(r \mathrm{~A}_{\text {Phys-Anx }}=0.78\right.$ 0.96) whereas genetic correlations between physical concerns and depression symptoms were weaker at all time points $\left(r \mathrm{~A}_{\text {Phys-Dep }}=0.15-0.87\right)$. Non-shared environmental correlations for physical concerns were also stronger for anxiety than depression ( $r \mathrm{E}_{\text {Phys-Anx }}=$ $\left.0.44-0.55, r E_{\text {Phys-Dep }}=0.18-0.39\right)$. These latter differences were significant at waves 3 and 5 [e.g. $r \mathrm{E}_{\text {Phys-Anx }}=0.51 \quad$ (95\% CI $\left.0.45-0.58\right), r \mathrm{E}_{\text {Phys-Dep }} 0.24$ (95\% CI $0.15-0.32)$ at wave 3 , mean age 15 years].

Social concerns had moderate to large genetic correlations with both anxiety and depression at all time points $\quad\left(r \mathrm{~A}_{\text {Soc-Anx }}=0.32-0.74, \quad r \mathrm{~A}_{\text {Soc-Dep }}=0.43-0.71\right)$. Non-shared environmental correlations with anxiety and depression were comparable at all time points $\left(r \mathrm{E}_{\text {Soc-Anx }}=0.12-0.39, \quad r \mathrm{E}_{\text {Soc-Dep }}=0.19-0.41\right)$. Similarly, mental concerns generally showed moderate to large genetic $\left(r \mathrm{~A}_{\text {Ment-Anx }}=0.46-0.86, \quad r \mathrm{~A}_{\text {Ment-Dep }}=0.04-0.71\right)$ and modest to moderate non-shared environmental correlations $\left(r \mathrm{E}_{\text {Ment-Anx }}=0.21-0.41, r \mathrm{E}_{\text {Ment-Dep }}=0.19-0.41\right)$ with both anxiety and depression at all waves. An exception was the lack of genetic correlation between mental concerns and depression at wave 2 (see footnote to Table S1). 
Table 2. Full and partial correlations between anxiety sensitivity dimensions and anxiety and depression across childhood, adolescence and early adulthood

\begin{tabular}{|c|c|c|c|c|c|c|c|}
\hline & & \multicolumn{3}{|l|}{ Full correlations } & \multicolumn{3}{|l|}{ Partial correlations } \\
\hline & & \multicolumn{3}{|c|}{ Anxiety sensitivity dimensions } & \multicolumn{3}{|c|}{ Anxiety sensitivity dimensions } \\
\hline & & Physical & Social & Mental & Physical & Social & Mental \\
\hline Wave 1. Child (mean age 8) & $\begin{array}{l}\text { Anxiety } \\
\text { Depression }\end{array}$ & $\begin{array}{l}\mathbf{0 . 5 2}(0.43 \text { to } 0.60) \\
\mathbf{0 . 2 6}(0.15 \text { to } 0.36)\end{array}$ & $\begin{array}{l}\mathbf{0 . 2 0}(0.09 \text { to } 0.31) \\
0.05(-0.06 \text { to } 0.16)\end{array}$ & $\begin{array}{l}\mathbf{0 . 4 2}(0.32 \text { to } 0.51) \\
\mathbf{0 . 3 0}(0.19 \text { to } 0.40)\end{array}$ & $\begin{array}{l}\mathbf{0 . 3 4}(0.24 \text { to } 0.44) \\
0.02(-0.09 \text { to } 0.13)\end{array}$ & $\begin{array}{r}0.09 \text { (to } 0.02 \text { to } 0.20) \\
-0.04(-0.15 \text { to } 0.07)\end{array}$ & $\begin{array}{l}\mathbf{0 . 1 7} \text { (0.06 to } 0.28) \\
\mathbf{0 . 1 4}(0.03 \text { to } 0.25)\end{array}$ \\
\hline Wave 2. Child (mean age 10) & $\begin{array}{l}\text { Anxiety } \\
\text { Depression }\end{array}$ & $\begin{array}{l}\mathbf{0 . 6 4}(0.56 \text { to } 0.71) \\
\mathbf{0 . 2 5}(0.09 \text { to } 0.33)\end{array}$ & $\begin{array}{l}\mathbf{0 . 2 6}(0.14 \text { to } 0.37) \\
\mathbf{0 . 1 5}(0.03 \text { to } 0.27)\end{array}$ & $\begin{array}{l}\mathbf{0 . 3 6}(0.25 \text { to } 0.46) \\
\mathbf{0 . 2 8}(0.16 \text { to } 0.39)\end{array}$ & $\begin{array}{c}0.53(0.44 \text { to } 0.61) \\
-0.01(-0.14 \text { to } 0.11)\end{array}$ & $\begin{array}{l}0.07(-0.05 \text { to } 0.19) \\
0.07(-0.05 \text { to } 0.19)\end{array}$ & $\begin{array}{l}0.04 \text { ( }-0.08 \text { to } 0.16) \\
\mathbf{0 . 1 8}(0.06 \text { to } 0.30)\end{array}$ \\
\hline Wave 3. Adolescent (mean age 15) & $\begin{array}{l}\text { Anxiety } \\
\text { Depression }\end{array}$ & $\begin{array}{l}\mathbf{0 . 6 7}(0.64 \text { to } 0.70) \\
\mathbf{0 . 4 3}(0.39 \text { to } 0.47)\end{array}$ & $\begin{array}{l}\mathbf{0 . 2 8}(0.23 \text { to } 0.33) \\
\mathbf{0 . 2 9}(0.24 \text { to } 0.34)\end{array}$ & $\begin{array}{l}\mathbf{0 . 4 7}(0.43 \text { to } 0.51) \\
\mathbf{0 . 4 2}(0.38 \text { to } 0.46)\end{array}$ & $\begin{array}{c}\mathbf{0 . 5 1}(0.47 \text { to } 0.53) \\
-0.01(-0.06 \text { to } 0.04)\end{array}$ & $\begin{array}{l}0.03 \text { (to } 0.02 \text { to } 0.08 \text { ) } \\
\mathbf{0 . 1 4}(0.09 \text { to } 0.19 \text { ) }\end{array}$ & $\begin{array}{l}\mathbf{0 . 1 5}(0.10 \text { to } 0.20) \\
\mathbf{0 . 2 0}(0.15 \text { to } 0.25)\end{array}$ \\
\hline Wave 4. Adolescent (mean age 17) & $\begin{array}{l}\text { Anxiety } \\
\text { Depression }\end{array}$ & $\begin{array}{l}0.71 \text { (0.68 to } 0.74) \\
0.51 \text { ( } 0.46 \text { to } 0.56)\end{array}$ & $\begin{array}{l}\mathbf{0 . 4 0}(0.34 \text { to } 0.45) \\
\mathbf{0 . 4 3}(0.38 \text { to } 0.48)\end{array}$ & $\begin{array}{l}\mathbf{0 . 4 8}(0.42 \text { to } 0.53) \\
\mathbf{0 . 5 4}(0.49 \text { to } 0.59)\end{array}$ & $\begin{array}{l}\mathbf{0 . 5 5} \text { (0.50 to } 0.59) \\
\mathbf{0 . 0 8}(0.01 \text { to } 0.15)\end{array}$ & $\begin{array}{l}0.06 \text { (0.00 to } 0.13) \\
\mathbf{0 . 2 2}(0.16 \text { to } 0.28)\end{array}$ & $\begin{array}{l}\mathbf{0 . 1 0}(0.03 \text { to } 0.17) \\
\mathbf{0 . 2 8}(0.22 \text { to } 0.34)\end{array}$ \\
\hline Wave 5. Adult (mean age 20) & $\begin{array}{l}\text { Anxiety } \\
\text { Depression }\end{array}$ & $\begin{array}{l}\mathbf{0 . 6 9}(0.66 \text { to } 0.72) \\
\mathbf{0 . 4 2}(0.37 \text { to } 0.47)\end{array}$ & $\begin{array}{l}\mathbf{0 . 2 6}(0.20 \text { to } 0.32) \\
\mathbf{0 . 1 9}(0.13 \text { to } 0.25)\end{array}$ & $\begin{array}{l}\mathbf{0 . 6 0}(0.56 \text { to } 0.64) \\
\mathbf{0 . 5 0}(0.45 \text { to } 0.55)\end{array}$ & $\begin{array}{c}\mathbf{0 . 4 5}(0.40 \text { to } 0.50) \\
-0.03(-0.10 \text { to } 0.04)\end{array}$ & $\begin{array}{l}0.05 \text { (to } 0.02 \text { to } 0.12 \text { ) } \\
0.03 \text { (-0.04 to } 0.10 \text { ) }\end{array}$ & $\begin{array}{l}\mathbf{0 . 2 3}(0.17 \text { to } 0.29) \\
\mathbf{0 . 1 5}(0.09 \text { to } 0.21)\end{array}$ \\
\hline
\end{tabular}

95\% Confidence intervals (CIs) are presented in parentheses. CIs not inclusive of zeros indicate significant correlations (in bold). Non-overlapping CIs mean significant difference between the values. Partial correlations controlled for all other variables within time (e.g. anxiety with physical concerns controlling for covariance with depression and social and mental concerns).

Results are presented for untransformed and unregressed variables for comparison with other published samples. Correlations were conducted on a random selection of one twin from each twin pair to ensure that the relatedness between pairs within the sample did not influence the associations between variables. 
Table 3. Genetic and non-shared environmental correlations between anxiety sensitivity dimensions and anxiety and depression across childhood, adolescence and early adulthood

\begin{tabular}{|c|c|c|c|c|c|c|c|}
\hline & & \multicolumn{3}{|l|}{ Genetic } & \multicolumn{3}{|c|}{ Non-shared environment } \\
\hline & & \multicolumn{3}{|c|}{ Anxiety sensitivity dimensions } & \multicolumn{3}{|c|}{ Anxiety sensitivity dimensions } \\
\hline & & Physical & Social & Mental & Physical & Social & Mental \\
\hline Wave 1 . Child (mean age 8 ) & $\begin{array}{l}\text { Anxiety } \\
\text { Depression }\end{array}$ & $\begin{array}{l}0.95 \text { ( } 0.45 \text { to } 1.00) \\
0.15 \text { ( }-0.78 \text { to } 0.81)\end{array}$ & $\begin{array}{l}0.46(-1.00 \text { to } 1.00) \\
0.43(-1.00 \text { to } 1.00)\end{array}$ & $\begin{array}{l}0.86(0.45 \text { to } 1.00) \\
0.48(-0.28 \text { to } 1.00)\end{array}$ & $\begin{array}{l}0.44(0.32 \text { to } 0.56) \\
0.24(0.08 \text { to } 0.39)\end{array}$ & $\begin{array}{l}0.22(0.08 \text { to } 0.37) \\
0.09(-0.06 \text { to } 0.24)\end{array}$ & $\begin{array}{l}0.23(0.09 \text { to } 0.37) \\
0.19(0.03 \text { to } 0.34)\end{array}$ \\
\hline Wave 2. Child (mean age 10) & $\begin{array}{l}\text { Anxiety } \\
\text { Depression }\end{array}$ & $\begin{array}{l}0.96(-1.00 \text { to } 1.00) \\
0.87(-1.00 \text { to } 1.00)\end{array}$ & $\begin{array}{l}0.32(-1.00 \text { to } 1.00) \\
0.54(-1.00 \text { to } 1.00)\end{array}$ & $\begin{array}{l}0.56(-1.00 \text { to } 1.00) \\
0.04 \text { ( }-1.00 \text { to } 1.00)\end{array}$ & $\begin{array}{l}0.52(0.39 \text { to } 0.62) \\
0.18(0.02 \text { to } 0.35)\end{array}$ & $\begin{array}{l}0.17(0.00 \text { to } 0.34) \\
0.04(-0.12 \text { to } 0.21)\end{array}$ & $\begin{array}{l}0.21 \text { (0.04 to } 0.38) \\
0.27(0.10 \text { to } 0.43)\end{array}$ \\
\hline Wave 3. Adolescent (mean age 15) & $\begin{array}{l}\text { Anxiety } \\
\text { Depression }\end{array}$ & $\begin{array}{l}0.78(0.61 \text { to } 0.87) \\
0.59(0.33 \text { to } 0.90)\end{array}$ & $\begin{array}{l}0.57(0.33 \text { to } 1.00) \\
0.67(0.31 \text { to } 1.00)\end{array}$ & $\begin{array}{l}0.59(0.37 \text { to } 0.81) \\
0.54(0.23 \text { to } 0.84)\end{array}$ & $\begin{array}{l}0.51(0.45 \text { to } 0.58) \\
0.24(0.15 \text { to } 0.32)\end{array}$ & $\begin{array}{l}0.22(0.13 \text { to } 0.29) \\
0.15(0.07 \text { to } 0.24)\end{array}$ & $\begin{array}{l}0.28(0.20 \text { to } 0.37) \\
0.28(0.19 \text { to } 0.37)\end{array}$ \\
\hline Wave 4. Adolescent (mean age 17) & $\begin{array}{l}\text { Anxiety } \\
\text { Depression }\end{array}$ & $\begin{array}{l}0.92(0.69 \text { to } 1.00) \\
0.58(0.41 \text { to } 0.93)\end{array}$ & $\begin{array}{l}0.46(0.11 \text { to } 0.88) \\
0.59(0.17 \text { to } 0.93)\end{array}$ & $\begin{array}{l}0.46(0.05 \text { to } 0.75) \\
0.56(0.09 \text { to } 0.83)\end{array}$ & $\begin{array}{l}0.54(0.46 \text { to } 0.61) \\
0.39(0.29 \text { to } 0.48)\end{array}$ & $\begin{array}{l}0.39(0.29 \text { to } 0.48) \\
0.31(0.21 \text { to } 0.41)\end{array}$ & $\begin{array}{l}0.40(0.29 \text { to } 0.49) \\
0.41(0.30 \text { to } 0.50)\end{array}$ \\
\hline Wave 5. Adult (mean age 20) & $\begin{array}{l}\text { Anxiety } \\
\text { Depression }\end{array}$ & $\begin{array}{l}0.90(0.67 \text { to } 1.00) \\
0.69(0.29 \text { to } 1.00)\end{array}$ & $\begin{array}{l}0.74(0.43 \text { to } 1.00) \\
0.71(0.37 \text { to } 1.00)\end{array}$ & $\begin{array}{l}0.83(0.56 \text { to } 1.00) \\
0.71(0.39 \text { to } 0.99)\end{array}$ & $\begin{array}{l}0.55(0.47 \text { to } 0.63) \\
0.30(0.19 \text { to } 0.40)\end{array}$ & $\begin{array}{l}0.12(0.01 \text { to } 0.23) \\
0.29(0.01 \text { to } 0.19)\end{array}$ & $\begin{array}{l}0.41(0.31 \text { to } 0.51) \\
0.32(0.22 \text { to } 0.43)\end{array}$ \\
\hline
\end{tabular}

95\% Confidence intervals (CIs) are presented in parentheses. CIs not inclusive of zeros indicate significant correlations. Non-overlapping CIs mean significant difference between the values.

Because of small non-significant shared environmental estimates on all variables, shared environmental correlations could not be reliably estimated. These are reported in the supplementary material (see Table S4) for the interested reader but cannot be meaningfully interpreted. 


\section{Discussion}

The current study reports cross-sectional analyses of shared and specific cognitive distortions in anxiety and depression at different development stages. This is the first study to investigate both phenotypic and genetic associations between anxiety sensitivity dimensions and anxiety and depressive disorder symptoms and to examine cross-sectional associations at five waves during childhood, adolescence and adulthood.

Partial correlations showed that the physical concerns dimension of anxiety sensitivity was associated with anxiety but not depression and shared greater genetic influences with anxiety than depression at all waves. Mental concerns were independently related to both anxiety and depression symptoms across development, with a tendency for stronger associations with depression than anxiety. Social concerns were not specifically associated with anxiety or depression in childhood and adulthood but tended to have stronger associations with depression than anxiety symptoms in adolescence. Genetic and non-shared environmental influences on mental and social concerns were moderately correlated with both anxiety and depression symptoms at all waves, although genetic correlations tended to be higher than non-shared environmental correlations. The results were similar at the three developmental periods, suggesting continuity over time in the patterns of associations between anxiety sensitivity dimensions and anxiety and depressive disorder symptoms. However, longitudinal research is needed to explore stability in the relationships between anxiety sensitivity dimensions, anxiety and depression.

Phenotypic results were largely in agreement with previous studies, finding stronger associations between physical concerns and anxiety, and between mental concerns and depression (Muris, 2002). However, they are in contrast to those suggesting that anxiety sensitivity is primarily associated with anxiety, and that associations with depression are driven by the co-occurrence between depression and anxiety (Joiner et al. 2002). Differential associations between anxiety sensitivity dimensions, anxiety and depression partially supported the CCS hypothesis, that anxiety and depression can be differentiated by divergent cognitive themes (Beck \& Perkins, 2001), and support a multifaceted model of anxiety sensitivity, consisting of distinct but related dimensions that play different roles in anxiety and depression. Future research should use anxiety sensitivity subscale scores, in addition to global scores, to clarify the broad associations identified between anxiety sensitivity and a range of anxiety and depressive disorders.

Our genetic results were largely in line with previous twin studies exploring aetiological associations between global anxiety sensitivity and anxiety and depression (Zavos et al. 2010). Moderate to substantial genetic overlap and modest non-shared environmental correlations between anxiety sensitivity dimensions and anxiety and depression symptoms are in accordance with the generalist genes hypothesis (Eley, 1997), highlighting that similarities between these constructs are driven by genetic rather than environmental factors. Furthermore, broad genetic associations are in line with high rates of co-occurrence between anxiety and depression (Seligman \& Ollendick, 1998) and between cognitive risk factors for both sets of symptoms (Zavos et al. 2010). Evidence for shared genetic effects has implications for molecular genetic studies, supporting the persuasive argument that including cases with anxiety and depression disorders would lead to increasing power to detect shared susceptibility loci (Hettema, 2008).

Conversely, evidence for phenotypic specificity in associations between anxiety sensitivity, anxiety and depression and unique environmental influences acting on these symptoms has clinical implications for therapeutic interventions. Identifying disorder-specific cognitive concerns, and also those shared between co-morbid disorders such as anxiety and depression, could continue to inform the tailoring of CBT programmes to a given diagnosis. For example, the physical concerns dimension of anxiety sensitivity relates to fear of biological symptoms of distress. These symptoms are central to anxiety but not so typical of depression, which is characterized more by sadness than fear. Conversely, mental and social concerns showed independent associations with both anxiety and depression, especially at later waves, suggesting there may be shared cognitive concerns in both sets of symptoms; for example, fear of losing mental control is captured in the mental concerns subscale and symptoms regarding control and distractibility are common in both anxiety and depressive disorders.

Associations between all anxiety sensitivity dimensions and anxiety suggest general modifications of anxiety-related cognitive concerns may be useful in CBT for anxiety disorders. However, anxiety represents a heterogeneous phenotype. Although beyond the scope of the current paper, future research would benefit from exploring specificity of associations between anxiety sensitivity dimensions and a range of anxiety disorder symptoms, independent of depression symptoms, to tailor cognitive interventions more precisely to specific anxiety disorders.

Associations between depression symptoms and mental and social concerns but not physical concerns dimensions of anxiety sensitivity are in line with current practice in CBT for depressive disorders, which focuses on modifying concerns surrounding 
cognitive and social symptoms rather than physical symptoms. Importantly, stronger associations in adolescence than in childhood and adulthood suggest that targeting social concerns may be most useful in adolescent depression. This developmental difference may be attributable to the fact that depression tends to emerge later than anxiety (Cohen et al. 1993) and fits with normal developmental trajectories of fears, which suggest that fears relating to social themes emerge later in young people than those relating to biological symptoms (Gullone, 2000). However, depression-specific research has implicated several other cognitive distortions in the development of depressive symptoms (Nolen-Hoeksema et al. 2008). Future research should aim to explore the content of depressive cognitions in more detail by combining multiple cognitive distortions within a single study.

\section{Limitations}

The genetically informative samples and multiple points are considerable strengths of the current study. However, the limitations of the study warrant consideration.

First, to ensure that age-appropriate inventories were used, measures differed across some waves. However, as all selected measures have previously been validated in similar samples and current analyses were not longitudinal, this should not limit the interpretation of our results (for longitudinal analyses of anxiety sensitivity, anxiety and depression, see Zavos et al. 2012a). Second, the extent to which young children can understand and report on internalizing symptoms is debated (Chorpita et al. 1996). Nevertheless, children as young as age 8 can make valid reports of internalizing symptoms (Michael \& Merrell, 1998; Merrell et al. 2002) and interpretations of anxiety symptoms (Muris et al. 2004). Given the internal replication of the results at all waves, in two different samples, our findings seem broadly applicable across development. Nonetheless, reliance on self-report data may be associated with shared method variance that could inflate the correlations. Third, measurement of anxiety sensitivity dimensions was limited by social and mental concerns dimensions containing only three items, resulting in lower internal consistency. However, the ASI and CASI are the only currently available self-report measures of anxiety sensitivity. Given the considerable evidence for a multifaceted construct, expanding measures of anxiety sensitivity to better capture social and mental concerns would be beneficial. Fourth, overlapping age ranges for waves 3 to 5 because of the inclusion of siblings could be argued to limit our ability to draw conclusions about patterns of associations across development. However, the majority of the sample fell within more discrete, non-overlapping age ranges at each wave, and when analyses were run without siblings the findings were very similar. We retained the siblings in our final models as their inclusion enhances the generalizability of our findings to non-twin populations.

With regard to twin analyses, the child sample was somewhat smaller than the adolescent/adult sample. Although considered large for phenotypic analyses, the paediatric sample had reduced power to detect shared environmental influences and parameter estimates resulted in larger CIs. It will be important to replicate the current results in larger paediatric twin studies. Additionally, there are some limitations inherent to the twin design, comprehensively discussed elsewhere (Plomin et al. 2012). These limitations have minimal and contrasting effects but parameter estimates should be taken as indicative rather than absolute values.

\section{Conclusions}

The results of the current study support and extend previous research examining specificity in associations between anxiety sensitivity dimensions, anxiety and depression and add to our growing understanding of co-morbidity between anxiety and depressive disorder symptoms. Specifically, anxiety sensitivity is a multifaceted construct. Distinct dimensions of anxiety sensitivity are differentially associated with anxiety and depression, indicating that anxiety and depressive disorder symptoms are characterized by both shared and symptom-specific cognitive distortions. Hence, the results from the current study are in agreement with the current DSM-5 classification that conceptualizes depression and anxiety as two separate, yet highly co-morbid, disorders. Furthermore, identifying specific and shared cognitions in anxiety and depression can inform the design of more precise clinical interventions for anxiety and depressive disorders across development.

\section{Note}

${ }^{1}$ All analyses for waves 3-5 were repeated excluding the sibling pairs to examine whether their more varied ages affected the results. There were no significant differences in the point estimates or in the interpretation of any of the results.

\section{Supplementary material}

For supplementary material accompanying this paper visit http://dx.doi.org/10.1017/S0033291714000828. 


\section{Acknowledgements}

We thank the families for their participation in this study and numerous staff and students from the Social Genetic Developmental Psychiatry Centre, Institute of Psychiatry, London and Goldsmiths, University of London.

Both the ECHO and G1219 studies were supported by a Medical Research Council Training Fellowship and a Career Development Award (T.C.E.). Waves 1-3 of G1219 were also funded by the W. T. Grant Foundation, the University of London Central Research fund (T.C.E.). Wave 4 of G1219 was supported by the Economic and Social Research Council (ESRC; RES-000-22-2206) and the Institute of Social Psychiatry (A.M.G.). H.M.B. and M.A.W. were supported by Ph.D. studentships awarded by the ESRC (ES/I010858/1ES/I010858/1) and the Alexander von Humboldt Foundation respectively.

\section{Declaration of Interest}

None.

\section{References}

AACAP (2007). Practice parameter for the assessment and treatment of children and adolescents with anxiety disorders. Journal of the American Academy of Child and Adolescent Psychiatry 46, 267-283.

Andrews G, Anderson T, Slade T, Sunderland M (2008). Classification of anxiety and depressive disorders: problems and solutions. Depression and Anxiety 25, 274-281.

Angold A, Costello EJ, Messer SC, Pickles A, Winder F, Silver D (1995). The development of a short questionnaire for use in epidemiological studies of depression in children and adolescents. International Journal of Methods in Psychiatric Research 5, 1-12.

Axelson DA, Birmaher B (2001). Relation between anxiety and depressive disorders in childhood and adolescence. Depression and Anxiety 14, 67-78.

Beck R, Perkins TS (2001). Cognitive content-specificity for anxiety and depression: a meta-analysis. Cognitive Therapy and Research 25, 651-663.

Birmaher B, Brent DA, Chiappetta L, Bridge J, Monga S, Baugher M (1999). Psychometric properties of the Screen for Child Anxiety Related Emotional Disorders (SCARED): a replication study. Journal of the American Academy of Child and Adolescent Psychiatry 38, 1230-1236.

Boker S, Neale M, Maes H, Wilde M, Spiegel M, Brick T, Spies J, Estabrook R, Kenny S, Bates T (2011). OpenMx: an open source extended structural equation modeling framework. Psychometrika 76, 306-317.

Brewin CR (1996). Theoretical foundations of cognitive-behavior therapy for anxiety and depression. Annual Review of Psychology 47, 33-57.

Brown HM, Trzaskowski M, Zavos HMS, Rijsdijk FV, Gregory AM, Eley TC (2012). Phenotypic and genetic structure of anxiety sensitivity in adolescence and early adulthood. Journal of Anxiety Disorders 26, 680-688.

Chorpita BF, Albano AM, Barlow DH (1996). Child Anxiety Sensitivity Index: considerations for children with anxiety disorders. Journal of Clinical Child Psychology 25, 77-82.

Chorpita BF, Yim L, Moffitt C, Umemoto LA, Francis SE (2000). Assessment of symptoms of DSM-IV anxiety and depression in children: a revised child anxiety and depression scale. Behaviour Research and Therapy 38, 835-855.

Cohen DJ, Dibble E, Grawe JM, Pollin W (1975). Reliably separating identical from fraternal twins. Archives of General Psychiatry 32, 1371-1375.

Cohen P, Cohen J, Kasen S, Velez CN, Hartmark C, Johnson J, Rojas M, Brook J, Streuning EL (1993). An epidemiological study of disorders in late childhood and adolescence-I. Age- and gender-specific prevalence. Journal of Child Psychology and Psychiatry 34, 851-867.

Dehon C, Weems CF, Stickle TR, Costa NM, Berman SL (2005). A cross-sectional evaluation of the factorial invariance of anxiety sensitivity in adolescents and young adults. Behaviour Research and Therapy 43, 799-810.

Eley TC (1997). General genes: a new theme in developmental psychopathology. Current Directions in Psychological Science 6, 90-95.

Eley TC, Gregory AM, Clark DM, Ehlers A (2007). Feeling anxious: a twin study of panic/somatic symptoms, anxiety sensitivity and heart-beat perception in children. Journal of Child Psychology and Psychiatry 48, 1184-1191.

Gregory AM, Buysse DJ, Willis TA, Rijsdijk FV, Maughan B, Rowe R, Cartwright S, Barclay NL, Eley TC (2011). Associations between sleep quality and anxiety and depression symptoms in a sample of young adult twins and siblings. Journal of Psychosomatic Research 71, 250-255.

Gullone E (2000). The development of normal fear: a century of research. Clinical Psychology Review 20, 429-451.

Hettema J (2008). What is the genetic relationship between anxiety and depression? American Journal of Medical Genetics. Part C, Seminars in Medical Genetics 148, 140-146.

Joiner TE, Schmidt NB, Schmidt KL, Laurent J, Catanzaro SJ, Perez M, Pettit JW (2002). Anxiety sensitivity as a specific and unique marker of anxious symptoms in youth psychiatric inpatients. Journal of Abnormal Child Psychology 30, 167-175.

Kendler KS, Heath AC, Martin NG, Eaves LJ (1987). Symptoms of anxiety and symptoms of depression. Same genes, different environments? Archives of General Psychiatry 44, 451-457.

Kovacs M (1985). The Children's Depression Inventory (CDI). Psychopharmacology Bulletin 21, 995-1124.

Lau J, Gregory A, Goldwin M, Pine D, Eley T (2007). Assessing gene-environment interactions on anxiety symptom subtypes across childhood and adolescence. Development and Psychopathology 19, 1129-1146.

McAdams TA, Gregory AM, Rowe R, Zavos H, Barclay NL, Lau JY, Maughan B, Eley TC (2013). The Genesis 12--9 (G1219) Study: a twin and sibling study of gene-environment interplay and adolescent development in the UK. Twin Research and Human Genetics 16, 134-143. 
McLaughlin EN, Stewart SH, Taylor S (2007). Childhood Anxiety Sensitivity Index factors predict unique variance in DSM-IV anxiety disorder symptoms. Cognitive Behaviour Therapy 36, 210-219.

McNally RJ, Rapee RM (1996). Anxiety sensitivity is distinguishable from trait anxiety. In Current Controversies in the Anxiety Disorders (ed. R. M. Rapee), pp. 214-227. Guilford Press: New York.

Merrell KW, McClun LA, Kempf KKG, Lund J (2002). Using self-report assessment to identify children with internalizing problems: validity of the internalizing symptoms scale for children. Journal of Psychoeducational Assessment 20, 223-239.

Michael KD, Merrell KW (1998). Reliability of children's self-reported internalizing symptoms over short to medium-length time intervals. Journal of the American Academy of Child and Adolescent Psychiatry 37, 194-201.

Muris P (2002). An expanded childhood anxiety sensitivity index: its factor structure, reliability, and validity in a non-clinical adolescent sample. Behaviour Research and Therapy 40, 299-311.

Muris P, Hoeve I, Meesters C, Mayer B (2004). Children's perception and interpretation of anxiety-related physical symptoms. Journal of Behavior Therapy and Experimental Psychiatry 35, 233-244.

Naragon-Gainey K (2010). Meta-analysis of the relations of anxiety sensitivity to the depressive and anxiety disorders. Psychological Bulletin 136, 128-150.

NICE (2011). CG113 Anxiety: NICE guidance (guidance.nice. org.uk/CG113). London: National Institute for Health and Care Excellence.

Nolen-Hoeksema S, Wisco BE, Lyubomirsky S (2008). Rethinking rumination. Perspectives on Psychological Science 3, 400-424.

Phan KL, Wager T, Taylor SF, Liberzon I (2002). Functional neuroanatomy of emotion: a meta-analysis of emotion activation studies in PET and fMRI. Neurolmage 16, 331-348.

Plomin R, DeFries JC, Knopik VS, Neiderhiser JM (2012). Behavioral Genetics. Worth Publishers: New York.

Price TS, Freeman B, Craig I, Petrill SA, Ebersole L, Plomin R (2000). Infant zygosity can be assigned by parental report questionnaire data. Twin Research 3, 129-133.

Rabian B, Embry L, MacIntyre D (1999). Behavioral validation of the Childhood Anxiety Sensitivity Index in children. Journal of Clinical Child Psychology 28, 105-112.

RDC Team (2010). R: A Language and Environment for Statistical Computing. R Foundation for Statistical Computing: Vienna, Austria.

Reiss S, McNally R (1985). Expectancy model of fear. In Theoretical Issues in Behavior Therapy (ed. S. Reiss and R. R. Bootzin), pp. 107-122. Academic Press: New York.

Reiss S, Peterson R, Gursky D, McNally R (1986). Anxiety sensitivity, anxiety frequency and the prediction of fearfulness. Behaviour Research and Therapy 24, 1-8.
Schmidt NB, Lerew DR, Joiner TE (1998). Anxiety sensitivity and the pathogenesis of anxiety and depression: evidence for symptom specificity. Behaviour Research and Therapy 36, 165-177.

Seligman LD, Ollendick TH (1998). Comorbidity of anxiety and depression in children and adolescents: an integrative review. Clinical Child and Family Psychology Review 1, 125-144.

Silverman W, Fleisig W, Rabian B, Peterson R (1991). Childhood anxiety sensitivity index. Journal of Clinical Child and Adolescent Psychology 20, 162-168.

Spence SH (1998). A measure of anxiety symptoms among children. Behaviour Research and Therapy 36, 545-566.

Taylor S (1999). Anxiety Sensitivity: Theory, Research and Treatment of the Fear of Anxiety. Lawrence Erlbaum Associates: Mahwah, NJ.

Taylor S, Koch WJ, Woody S, McLean P (1996). Anxiety sensitivity and depression: how are they related? Journal of Abnormal Psychology 105, 474-479.

Vytal K, Hamann S (2010). Neuroimaging support for discrete neural correlates of basic emotions: a voxel-based meta-analysis. Journal of Cognitive Neuroscience 22, 2864-2885.

Walsh T, Stewart S, McLaughlin E, Comeau N (2004). Gender differences in Childhood Anxiety Sensitivity Index (CASI) dimensions. Journal of Anxiety Disorders 18, 695-706.

Waszczuk MA, Zavos HMS, Eley TC (2013). Genetic and environmental influences on relationship between anxiety sensitivity and anxiety subscales in children. Journal of Anxiety Disorders 27, 475-484.

Weems CF, Hammond-Laurence K, Silverman WK, Ferguson C (1997). The relation between anxiety sensitivity and depression in children and adolescents referred for anxiety. Behaviour Research and Therapy 35, 961-966.

Weems CF, Hammond-Laurence K, Silverman WK, Ginsburg GS (1998). Testing the utility of the anxiety sensitivity construct in children and adolescents referred for anxiety disorders. Journal of Clinical Child Psychology 27, 69-77.

Wright K, Asmundson G, McCreary D, Stewart S, McLaughlin E, Comeau M, Walsh T (2010). Confirmatory factor analysis of the childhood anxiety sensitivity index: a gender comparison. Cognitive Behaviour Therapy 39, 225-235.

Zavos H, Rijsdijk F, Gregory A, Eley T (2010). Genetic influences on the cognitive biases associated with anxiety and depression symptoms in adolescents. Journal of Affective Disorders 124, 45-53.

Zavos HM, Gregory AM, Eley TC (2012a). Longitudinal genetic analysis of anxiety sensitivity. Developmental Psychology 48, 204-212.

Zavos HM, Rijsdijk FV, Eley TC (2012b). A longitudinal, genetically informative, study of associations between anxiety sensitivity, anxiety and depression. Behavior Genetics 42, 592-602. 